\title{
Численное моделирование характеристик солнечных элементов на основе GaPNAs/Si гетероструктур и GaN нитевидных нанокристаллов
}

\author{
(C) А.М. Можаров*, Д.А. Кудряшов*, А.Д. Большаков*, Г.Э. Цырлин*+, \\ А.С. Гудовских ${ }^{*}$, И.С. Мухин ${ }^{*+}$ \\ * Санкт-Петербургский национальный исследовательский Академический университет \\ Российской академии наук, \\ 194021 Санкт-Петербург, Россия \\ + Университет ИТМО, \\ 197101 Санкт-Петербург, Россия \\ - Санкт-Петербургский государственный электротехнический университет «ЛЭТИ» \\ им. В.И. Ульянова (Ленина), \\ 197376 Санкт-Петербург, Россия \\ E-mail: mozharov@spbau.ru
}

(Получена 27 апреля 2016 г. Принята к печати 10 мая 2016 г.)

С помощью методов численного моделирования рассмотрены режимы работы и определены конструкции солнечных элементов комбинированной размерности на основе планарной гетероструктуры GaPNAs/Si и массива $\mathrm{GaN}$ нитевидных нанокристаллов. Показано, что массив $\mathrm{GaN}$ нитевидных нанокристаллов обладает антиотражающими свойствами на уровне не хуже $2.5 \%$ при освещении солнечным спектром AM1.5D. Наибольшее влияние на эффективность работы солнечных элементов оказывают времена жизни неосновных носителей заряда и толщина фотоактивных слоев. Продемонстрировано, что эффективность двухпереходных солнечных элементов, состоящих из перехода на основе твердого полупроводникового раствора GaPNAs и массива GaN нитевидных нанокристаллов на Si подложке, достигает 32\% при AM1.5D.

\section{1. Введение}

В последнее время в связи с многочисленными достижениями в технологии роста полупроводниковых соединений все отчетливее становится перспектива прямой интеграции полупроводников $\mathrm{A}^{\mathrm{III}} \mathrm{B}^{\mathrm{V}}$ и кремния. Данная интеграция позволит создавать монолитные оптоэлектронные приборы с совершенно новыми характеристиками. Работы по непосредственному росту GaAs на Si-подложках ведутся достаточно давно [1,2], однако наличие относительно большого рассогласования в параметрах кристаллических решеток $(\sim 4 \%)$ данных материалов практически во всех экспериментах приводит к формированию большого количества дислокаций несоответствий на гетероинтерфейсе $\left(10^{6}-10^{7} \mathrm{~cm}^{-2}\right)$, появлению каналов стока неосновных носителей, что драматическим образом влияет на эффективность работы приборов. Полупроводниковое соединение GaP схоже по параметру решетки с кремнием, но при этом за счет того, что $\mathrm{GaP}$ является непрямозонным полупроводником [3], эффективность оптоэлектронных приборов (диодов, лазеров, фотовольтаических преобразователей и т.д.) на его основе относительно не высока. Добавление небольшого количества азота (менее 4\%) в $\mathrm{GaP}$ существенно меняет его свойства, делая полупроводниковый твердый раствор GaPN прямозонным $[4,5]$ и увеличивая его коэффициент поглощения. Отметим при этом, что значение ширины запрещенной зоны GaPN составляет около 2 эВ [3], что не является оптимальным при создании двухпереходных солнечных элементов (СЭ) на основе $\mathrm{GaPN} / \mathrm{Si}$.
Разбавленные нитридные твердые растворы GaPNAs за счет варьирования содержания As и $\mathrm{P}$ могут быть решеточно согласованы с ростовой подложкой $(\mathrm{Si})$. При этом появляется возможность независимого управления значением ширины запрещенной зоны в широком диапазоне значений 1.5-2 эВ [6]. Как было экспериментально и теоретически показано в работах [7,8], СЭ с несколькими переходами на основе системы материалов GaPNAs/Si могут быть решеточно согласованными и обладать высокой эффективностью при низкой стоимости подложки.

В данной работе рассматриваются СЭ комбинированной размерности на основе GaPNAs/Si, в которых эмиттерный слой верхнего перехода заменен на массивы $\mathrm{GaN}$ или GaP нитевидных нанокристаллов (ННК). Данный подход имеет ряд преимуществ, включающий эффективную пассивацию лицевой поверхности верхнего перехода GaPNAs и формирование широкозонного окна при росте массива ННК, высокие антиотражающие и транспортные свойства массива ННК [9].

ННК на основе нитридных соединений, обладая высоким аспектным отношением длины ННК к его диаметру, за счет релаксации упругих напряжений на боковых поверхностях ННК обеспечивают бездислокационный рост кристаллов на полупроводниковых подложках различного типа, в том числе с большим рассогласованием по параметру кристаллической решетки [10,11]. Данные особенности ННК открывают перспективы создания оптоэлектронных приборов на основе интеграции $\mathrm{Si}$ технологий и III-нитридных соединений. 


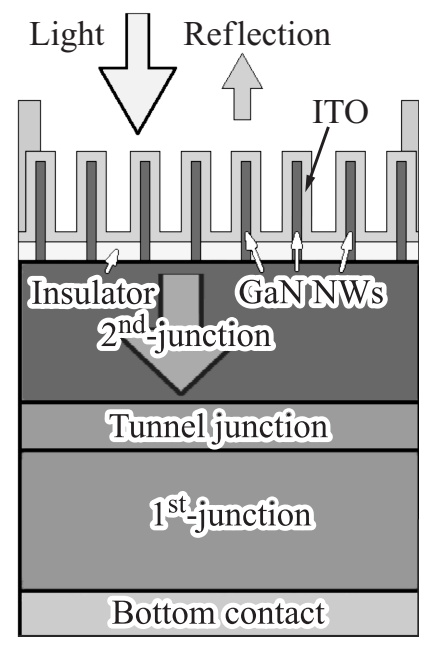

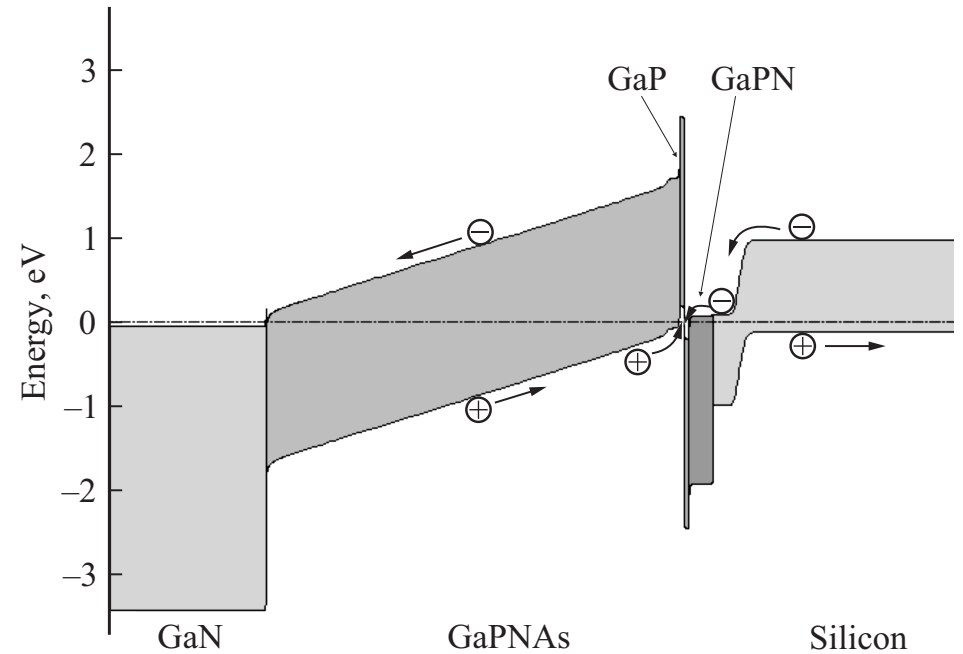

Рис. 1. $a-$ схематическое изображение двухпереходного СЭ на основе гетероструктуры GaPNAs/Si и GaN HHK. $b-$ зонная структура СЭ. Пунктирной линией отмечено положение уровня Ферми.

\section{2. Детали моделирования}

На рис. $1, a$ представлено схематическое изображение двухпереходного СЭ на основе планарной решеточносогласованной гетероструктуры GaPNAs/Si и GaN HHK. Конструкция рассматриваемого двухпереходного СЭ состоит из нижнего $p-n$-перехода в $\mathrm{Si}$ и верхней $p-i-n$-структуры на основе GaPNAs ( $p$-, $i$-слои) и $\mathrm{GaN}$ ННК (n-слой). Массив GaN ННК выступает в качестве эмиттерного слоя верхнего каскада, а также в качестве широкозонного окна и эффективного антиотражающего покрытия. В качестве лицевого контакта для сбора фотоиндуцированных носителей с $\mathrm{GaN}$ HНК рассматривается прозрачный проводящий электрод на основе ITO, отделенный от планарной гетероструктуры тонким прозрачным диэлектрическим слоем. Омические потери в верхнем и нижнем контактах не учитывались. Туннельный диод сформирован на основе $\mathrm{GaP}$, при этом был введен буферный слой $\mathrm{GaPN}$, также выполняющий роль широкозонного окна для нижнего перехода. Зонная структура и состав слоев рассматриваемого СЭ представлены на рис. $1, b$ и в таблице соответственно.

Спектры поглощения для полупроводниковых слоев GaPNAs соответствовали экспериментальным данным из работы [6], для слоев буферного $\mathrm{GaPN}-$ из работы [12]. Значения ширины запрещенной зоны для $\mathrm{GaP}_{0.893} \mathrm{~N}_{0.037} \mathrm{As}_{0.07}$ и $\mathrm{GaP}_{0.98} \mathrm{~N}_{0.02}$ составляли 1.78 эВ [6] и 2.0 эВ $[3,13]$ соответственно. Эффективная масса электронов для GaPNAs равнялась аналогичному значению для $\mathrm{GaPN}$ и составляла $0.9 m_{e}$ [14], где $m_{e}-$ масса электрона. Так как при добавлении азота валентная зона в GaPNAs и GaPN изменяется слабо, то значение эффективной массы дырок равнялось соответствующему значению для $\mathrm{GaP}$ и составляло $0.83 m_{e}$ [6]. $\mathrm{B}$ соответствии с экспериментальными данными, пред- ставленными в работах [5,15], значение подвижностей электронов и дырок составляло $50 \mathrm{~cm}^{2} \mathrm{~B}^{-1} \mathrm{c}^{-1}$. Значения разрыва зон проводимости на гетерограницах $\mathrm{GaP} / \mathrm{GaPN}$ и $\mathrm{GaP} / \mathrm{GaPNAs}$ составляли 0.27 эB [13] и 0.5 эВ [16] соответственно. Значение разрыва валентных зон на гетерогранице $\mathrm{GaP} / \mathrm{GaPN}$ составляло 0.03 эB [13], при этом значения энергии сродства к электрону для $\mathrm{GaP}$, $\mathrm{GaPN}$ и GaPNAs составляли 3.8, 4.07 и 4.3 эВ соответственно. Время жизни неосновных носителей заряда для слоя $\mathrm{GaPN}$ и для электронов и дырок составляло $0.3 \mathrm{Hc}$.

При моделировании режимов работы СЭ использовались следующие параметры для кремниевой подложки [17]: подвижности в кремниевой подложке для электронов и дырок составляли 520 и $235 \mathrm{~cm}^{2} \mathrm{~B}^{-1} \mathrm{c}^{-1}$ соответственно, при этом подвижности в верхнем $n$-легированном слое кремния для электронов и дырок составляли 260 и $140 \mathrm{~cm}^{2} \mathrm{~B}^{-1} \mathrm{c}^{-1}$ соответственно, времена жизни для электронов и дырок составляли 260 и 140 нс соответственно. Поверхностная рекомбинация на тыльном контакте при моделировании не учитывалась.

Параметры слоев двухпереходного СЭ на основе гетероструктуры GaPNAs/Si и GaN HНК

\begin{tabular}{l|l|c|c}
\hline \multicolumn{1}{c|}{ Материал } & $\begin{array}{c}E_{g}, \\
\text { эВ }\end{array}$ & $\begin{array}{c}\text { Толщина, } \\
\text { мкм }\end{array}$ & $\begin{array}{c}\text { Уровень } \\
\text { легирования, см }{ }^{-3}\end{array}$ \\
\hline$n$-GaN HНК & 3.4 & 1.4 & $5 \cdot 10^{18}$ \\
$i$-GaPNAs & 1.78 & $1.0-4.0$ & $1 \cdot 10^{12}$ \\
$p$-GaPNAs & 1.78 & 0.05 & $1 \cdot 10^{18}$ \\
$p^{++}-\mathrm{GaP}$ & 2.26 & 0.02 & $3 \cdot 10^{20}$ \\
$n^{++}-\mathrm{GaP}$ & 2.26 & 0.02 & $3 \cdot 10^{20}$ \\
$n$-GaPN & 2.0 & 0.1 & $1 \cdot 10^{18}$ \\
$n$-Si & 1.12 & 0.1 & $1 \cdot 10^{18}$ \\
$p$-Si (подложка) & 1.12 & 300 & $2.5 \cdot 10^{17}$ \\
\end{tabular}



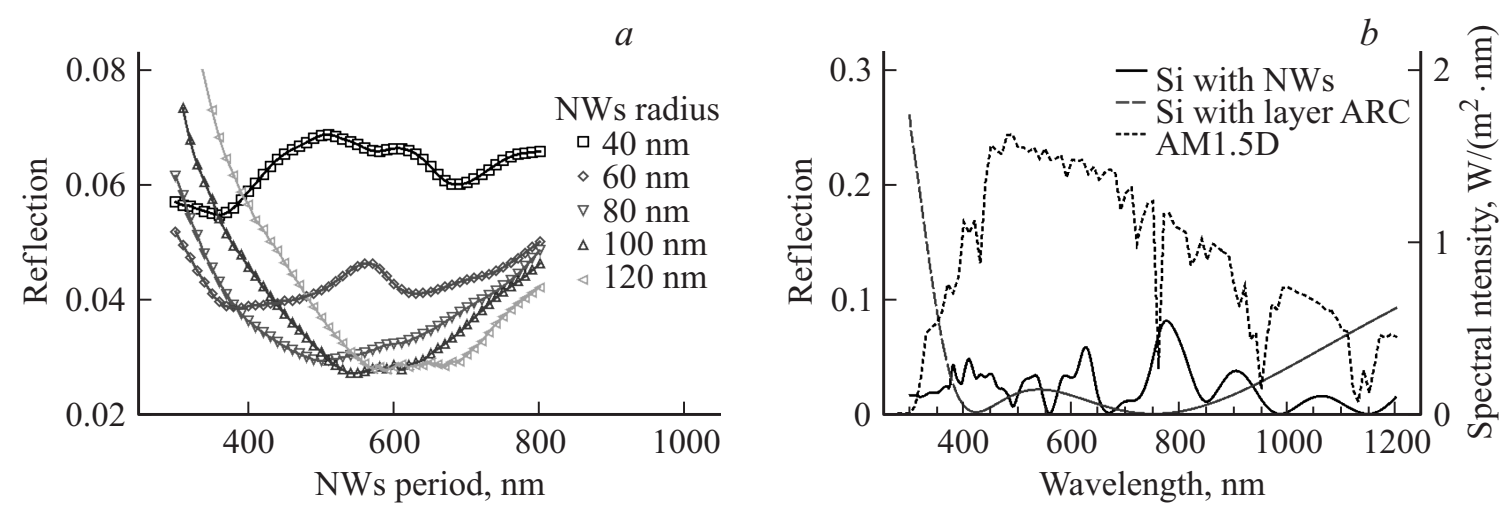

Рис. 2. $a-$ зависимость интегрального коэффициента отражения СЭ от периода расположения ННК и их радиуса. $b-$ спектральная зависимость коэффициента отражения СЭ с ННК и СЭ с двухслойным просветляющим покрытием при освещении солнечным излучением со спектром AM1.5D. Длина волны ограничена областью поглощения света в кремниевом переходе СЭ.

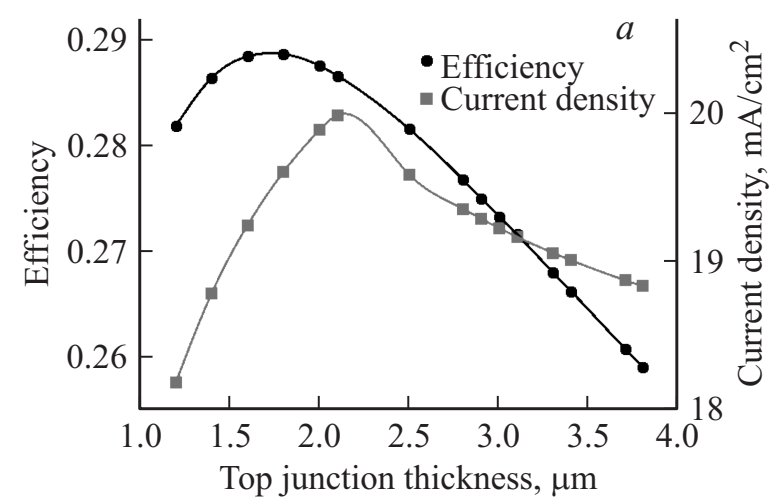

Рис. 3. Звисимости $I_{\mathrm{SC}}$, эффективности $(a)$ и зависимость $U_{\mathrm{OC}}$ жизни носителей заряда 10 нс.

Численное моделирование антиотражающих свойств рассматриваемого СЭ выполнялось с помощью программного комплекса CST Microwave. Массив ННК рассматривался в виде гексагонально-упорядоченных цилиндров с одинаковыми радиусами и длиной. Моделирование электрических характеристик СЭ выполнялось с помощью квазиодномерной модели методом Ньютона с использованием статистики Ферми-Дирака. При описании туннельного диода $\mathrm{GaP}$ использовалась модель межзонного туннелирования [18].

\section{3. Результаты моделирования}

На первом этапе было проведено моделирование антиотражающих свойств CЭ с массивом $\mathrm{GaN}$ HНК с учетом верхнего контакта на основе ITO толщиной 100 нм. На рис. 2, а представлена зависимость интегрального коэффициента отражения СЭ от периода расположения ННК и их радиуса. Начиная со значения радиуса ННК, равного 80 нм и выше, данная зависимость имеет локальный минимум. Оптимальное значение радиуса ННК составляет 100-120 нм, при этом значение коэффициента отражения составляет около $2.5 \%$. На рис. $2, b$ представлена спектральная зависимость коэффициента отражения СЭ с ННК при данных параметрах при освещении солнечным излучением со спектром AM1.5D. Для сравнения приведен спектр отражения от поверхности $\mathrm{Si}$ с двухслойным просветляющим покрытием на основе $\mathrm{SiO}_{2} / \mathrm{TiO}_{2}(90 \mathrm{Hм} / 60 \mathrm{Hм})$, интегральный коэффициент отражения которой составляет $2.1 \%$. Также было проведено моделирование распространения падающего излучения для СЭ с оптимальными геометрическими параметрами массива ННК. Показано, что в широком спектральном диапазоне в ННК реализуется волноводный режим распространения света, что определяет малые потери на отражение. Отметим, что падающее излучение с длинами волн более 365 нм (соответствует ширине запрещенной зоны $\mathrm{GaN}$ ) не поглощается в ННК. Дальнейшее численное моделирование электрических характеристик СЭ выполнялось с учетом спектров отражения, полученных при оптимальных морфологических параметрах ННК.

При оптимизации конструкции двухпереходного СЭ также варьировались значения толщины $i$-области GaPNAs в верхнем переходе и времени жизни носителей в данном слое. Параметры Si перехода были зафикси- 


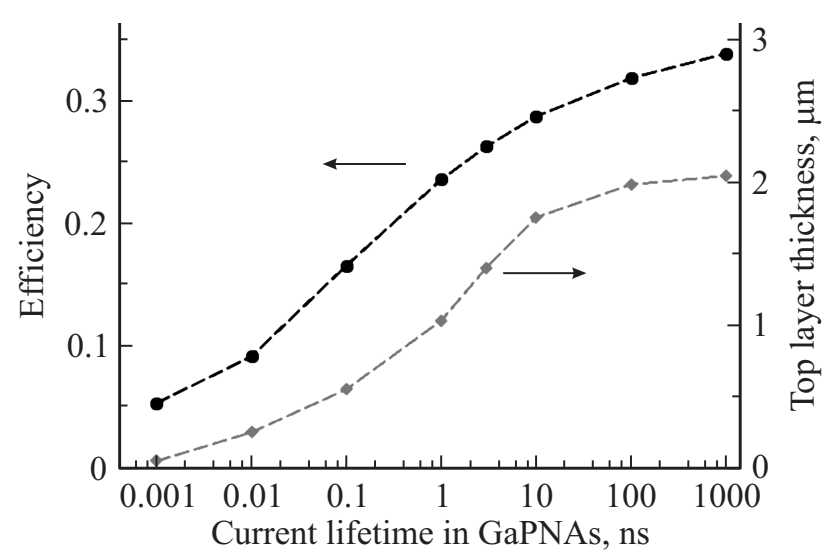

Рис. 4. Зависимость эффективности СЭ от времени жизни носителей в $i$-слое GaPNAs при оптимальных значениях толщин фотоактивных слоев.

рованы. Для достижения максимальной эффективности СЭ необходимо выполнение условия согласования по току обоих переходов. Другими словами, значение тока короткого замыкания, генерируемого каждым переходом СЭ под воздействием внешнего излучения (AM1.5D), должно быть одинаковым. Согласование по току переходов СЭ достигалось за счет варьирования толщины $i$-GaPNAs.

На рис. 3 представлены зависимости тока короткого замыкания $I_{\mathrm{SC}}$, напряжения холостого хода $U_{\mathrm{OC}}$, фактора заполнения и эффективности СЭ от толщины активной области $i$-GaPNAs при времени жизни носителей заряда 10 нс. Представленные зависимости показывают, что при малых значениях толщины $i$-GaPNAs область фотогенерации неосновных носителей заряда в верхнем переходе мала, что в свою очередь ограничивает значение тока короткого замыкания. При этом условие согласования переходов по току не выполняется и эффективность работы СЭ не высока. При слишком большом значении толщины $i$-GaPNAs, с одной стороны, возможно несбалансированное поглощение света в верхнем каскаде и, как следствие, рассогласование каскадов по току. С другой стороны, увеличение толщины $i$-области приводит к уменьшению напряженности встроенного электрического поля между $p$-, и $n$-областями верхнего каскада и, как следствие, к снижению эффективности разделения фотогенерируемых носителей.

Диффузионная длина неосновных носителей заряда или их времена жизни являются наиболее важным параметром, влияющим на эффективность и дизайн СЭ. На рис. 4 представлена зависимость эффективности СЭ от времени жизни носителей в $i$-слое GaPNAs при оптимальных значениях толщины данного слоя. Рост значения времени жизни носителей заряда в $i$-GaPNAs приводит к уменьшению вероятности рекомбинации носителей и увеличению вероятности разделения носителей встроенным электрическим полем, что в свою очередь приводит к увеличению значений тока короткого замыкания и напряжения холостого хода СЭ, а следовательно, и эффективности. При временах жизни носителей более 10 нс эффективность СЭ превышает 30\%, достигая $32 \%$ при значении времени жизни $\sim 100$ нс.

Следует отметить, что температуры синтеза планарных слоев GaPNAs и массивов GaN HНК с помощью метода молекулярно-пучковой эпитаксии сильно отличаются, что может внести определенные ограничения на формирование СЭ в одном технологическом цикле. В качестве одного из возможных путей преодоления данного технологического ограничения можно рассматривать замену массивов GaN HНК на массивы GaP ННК. При этом, так как ширина запрещенной зоны $\mathrm{GaP}$ значительно ниже по сравнению с $\mathrm{GaN}$ и близка к значениям GaPNAs, часть падающего излучения будет поглощаться непосредственно в $\mathrm{GaP}$ ННК, что приведет к общему снижению тока короткого замыкания СЭ и его эффективности. В случае использования $\mathrm{GaP}$ ННК появляется возможность создания трехпереходных СЭ, верхний переход которых сформирован непосредственно в ННК.

\section{4. Заключение}

В работе рассмотрены режимы работы СЭ комбинированной размерности на основе планарной гетероструктуры GaPNAs/Si и массива GaN HНК. Данные полупроводниковые соединения обладают необходимыми кристаллическими, оптическими и электронными свойствами для создания высокоэффективных фотовольтаических преобразователей на $\mathrm{Si}$ подложках. Массив $\mathrm{GaN}$ ННК обеспечивает антиотражающие свойства на уровне не хуже $2.5 \%$.

Наибольшее влияние на эффективность работы СЭ оказывают времена жизни неосновных носителей заряда в фотоактивных слоях. С помощью численного моделирования показано, что при временах жизни носителей заряда в слоях GaPNAs, превышающих значение. 100 нс, эффективность СЭ превосходит 32\%.

Работа выполнена при финансовой поддержке Министерства образования и науки Российской Федерации (RFMEFI61615X0040).

Авторы выражают благодарность акад. Ж.И. Алфёрову за полезные обсуждения результатов и поддержку работы.

\section{Список литературы}

[1] Y. Fujimoto, H. Yonezu, K. Momose, A. Utsimi, Y. Furukawa, J. Cryst. Growth, 227 (228), 491 (2001).

[2] K. Momose, H. Yonezu, Y. Fujimoto, K. Ojima, Y. Furukawa, A. Utsumi, K. Aiki. Jpn J. Appl. Phys., 41 (12R), 7301 (2002).

[3] S. Adachi. Properties of semiconductor alloys: group-IV, III-V and II-VI semiconductors (John Wiley \& Sons, 2009) v. 28, p. 400.

[4] H.P. Xin, C.W. Tu. Appl. Phys. Lett., 77 (14), 2180 (2000). 
[5] Z. Liu, H. Kawanami, I. Sakata. Appl. Phys. Lett., 96 (3), 032106 (2010).

[6] J.F. Geisz, D.J. Friedman, S.R. Kurtz. Proc 29th IEEE PVSC (New Orleans, LA, 2002) p. 864.

[7] Д.А. Кудряшов, А.С. Гудовских, Е.В. Никитина, А.Ю. Егоров. ФТП, 48 (3), 396 (2014).

[8] J.F. Geisz, D.J. Friedman. Semicond. Sci. Techn., 17 (8), 769 (2002).

[9] A. Mozharov, A. Bolshakov, G. Cirlin, I. Mukhin. PSS RRL, 9 (9), 507 (2015).

[10] F. Glas, Phys. Rev. B, 74, 121302 (2006).

[11] M. Bjork, B. Ohlsson, T. Sass, A. Persson, C. Thelander, M. Magnusson, K. Deppert, L. Wallenberg, L. Samuelson. Nano Lett., 2, 87 (2002).

[12] G. Leibiger, V. Gottschalch, M. Schubert, G. Benndorf, R. Schwabe. Phys. Rev. B, 65, 245207 (2002)

[13] K. Umeno, S.M. Kim, Y. Furukawa, H. Yonezu, A. Wakahara. J. Cryst. Growth, 301, 539 (2007).

[14] H.P. Xin, C.W. Tu. Appl. Phys. Lett., 77, 2180 (2000).

[15] M. Gungerich, P.J. Klar, W. Heimbrodt, G. Weiser, A. Lindsay, C. Harris, E.P. O'Reilly. Dilute III-V Nitride Semiconductors and Material Systems (Germany, Springer, 2008) v. 15, p. 592.

[16] G. Biwa, H. Yaguchi, K. Onabe, Y. Shiraki. J. Cryst. Growth, 195, 574 (1998)

[17] M.E. Law, E. Solley, M. Liang, D.E. Burk et al. IEEE Electron Dev. Lett., 12 (8), 401 (1991).

[18] G.A.M. Hurkx, D.B.M. Klaassen, M.P.G. Knuvers. IEEE Trans. Electron Dev., 39, 331 (1992).

Редактор А.Н. Смирнов

\section{Numerical modeling of properties of solar cell based on GaPNAs/Si heterostructure and $\mathrm{GaN}$ nanowires}

A.M. Mozharov*, D.A. Kudryashov*, A.D. Bolshakov*, G.E. Cirlin*+, A.S. Gudovskikh*•, I.S. Mukhin*+

* St. Petersburg Academic University, 194021 St. Petersburg, Russia

+ ITMO University, 197101 St. Petersburg, Russia

- St. Petersburg Electrotechnical University "LETI", 197376 St. Petersburg, Russia

Abstract In this paper design of solar cells based on planar GaPNAs/Si heterostructure and GaN nanowires is studied by means of numerical modeling. It's shown that GaN nanowires have excellent antireflecting properties (reflection is less than 2.5\%) under AM1.5D illumination condition. Carrier life time and the photoactive layers thicknesses have the main influence on solar cell efficiency. It's demonstrated that efficiency of 2-junction solar cell based on GaPNAs layers and GaN nanowires on Si substrate can reach $32 \%$ under AM1.5D illumination. 